\title{
INCREASE RESISTANT RATES AND ESBL PRODUCTION BETWEEN E. COLI ISOLATES CAUSING URINARY TRACT INFECTION IN YOUNG PATIENTS FROM IRAN
}

\section{Babak Pourakbari ${ }^{1}$, Farzad Ferdosian ${ }^{2}$, Shima Mahmoudi ${ }^{1}$, Mostafa Teymuri ${ }^{1}$, Farah Sabouni ${ }^{3}$, Hossein Heydari ${ }^{4}$, Mohammad Taghi Haghi Ashtiani ${ }^{5}$, Setareh Mamishi ${ }^{1,3 *}$}

${ }^{1}$ Pediatrics Infectious Diseases Research Center, Tehran University of Medical Sciences, Tehran, Iran; ${ }^{2}$ Departament Pediatrics Infectious Disease, Yazd University of Medical Sciences; ${ }^{3}$ Department of Infectious Disease, School of Medicine, Tehran University of Medical Sciences, Tehran, Iran; ${ }^{4}$ Departament Pediatrics Infectious Disease, Qom University of Medical Sciencies; ${ }^{5}$ Department of pathology, School of Medicine, Tehran University of Medical Sciences, Tehran, Iran.

Submitted: December 22, 2010; Returned to authors for corrections: April 06, 2011; Approved: January 16, 2012.

\begin{abstract}
Emerging antimicrobial resistance rates and Extended-spectrum beta-lactamase producing Escherichia coli recovered from urinary tract infections (UTI) is an increasing problem in specific regions, limiting therapeutic options. One hundred E. coli isolates causing UTI in patients with age from 2 months to 12 years admitted at CMC in the period of April 2009 to March 2010 were tested for antibiotic susceptibility using the disk diffusion method. Surprisingly high resistance rates were recorded for E. coli against TMP/SMX (84\%), cefalotin (66\%), cefuroxime (50\%), cefixime (50\%) and ceftriaxone (45\%). Antimicrobial susceptibility of $E$. coli isolates was followed by meropenem (98\%), amikacin (95\%), nitrofurantoin (91\%) and gentamicin (68\%). Extended spectrum beta-lactamase production, was observed in $32 \%$ of community and $42 \%$ of nosocomial isolates. The results of this study and numerous observations regarding the increasing resistance to these antibiotics, in several countries, emphasize the need for local populationspecific surveillance for guiding empirical therapy for UTI in children.
\end{abstract}

Key words: E. coli, Urinary Tract Infection, Antimicrobial susceptibility, ESBL

Urinary tract infection (UTI) is one of the most common bacterial diseases in children. Early diagnosis and quick antimicrobial treatment are required to minimize renal scarring and progressive kidney damage. In patients with suspected UTI, antibiotic treatment is usually started empirically, before urine culture results are available. Unfortunately, antibiotic resistance has become an increasingly critical problem in many countries like Iran $(1,2)$.

A significant emerging problem is the Extended spectrum beta-lactamase (ESBL) mechanism of resistance (3). ESBLs are beta-lactamases that hydrolyze extended spectrum cephalosporins with an oxyimino side chain (4). The present study was carried out with one hundred E. coli consecutive isolates (nonduplicate) originating from the urinary tract infections collected from April 2009 to March 2010.

The Children Medical Center (CMC) is a referral tertiary teaching hospital admitting patients from all regions of Iran. The study population consisted of all patients (50 hospitalized

*Corresponding Author. Mailing address: Department of Pediatric Infectious Diseases, Children Medical Center Hospital School of Medicine, Tehran University of Medical Sciences, No.62, Gharib St., Keshavarz Blvd., Tehran, Iran.; Tel: +98- 21- 6642- 8996 Fax: +98- 21- 6642- 8996.; E-mail: smamishi@sina.tums.ac.ir 
and 50 community acquired) having positive urine cultures with a colony count of $\geq 10^{5}$ colony forming units per milliliter for midstream urine samples, $\geq 10^{4}$ for samples collected by catheter from infants and small children and growth of any count of bacteria for samples obtained as bladder punctures via suprapubic aspiration (5). Community acquired isolates were defined as a culture collection from a patient not admitted to the hospital whilst samples originating from patients hospitalised for $48 \mathrm{hrs}$ or more on general or specialized wards were considered nosocomial. All E. coli isolates were microbiologically identified in the microbiology laboratory of CMC using standard biochemical identification methods (6). These samples had been processed on blood agar and MacConkey medium with a standard loop and were incubated at $37^{\circ} \mathrm{C}$ overnight.

The minimum inhibitory concentrations (MIC) of cefalotin, gentamicin, cefixime, cefuroxime, trimethoprim/ sulfamethoxazole, meropenem, nitrofurantoin, ceftriaxone and amikacin were determined by using the E-test ( $\mathrm{AB}$ bioMérieux, Solna, Sweden). Also ESBLs were detected by phenotypic confirmation with ceftazidime, ceftazidime-clavulanate and cefotaxime, cefotaxime-clavulanate disks, as recommended by the NCCLS (6). All statistical analysis was performed using SPSS software, version 11.5 and P-value <0.05 indicating significance.

The antimicrobial susceptibility for 9 selected antimicrobial agents of different classes against $E$. coli isolates were summarized in Table 1. Meropenem (98\%), amikacin (95\%) and nitrofurantoin (91\%) showed highest percent susceptibility against $E$. coli in this study. The high resistance rates against trimethoprim-sulfamethoxazole (84\%), cefalotin , cefuroxime, cefixime $(>50 \%)$ was also observed among these isolates.

This study and also the previous report of our center shows that there are some differences between the rate of antimicrobial resistance in Tehran and all other places in the world (7-9).
The spread of antimicrobial resistance among bacterial pathogens in Iran has emerged as an important challenge for the Iranian medical community. The increasing frequency of trimethoprim-sulfamethoxazole resistance is troublesome. The prevalence of resistance to this antibiotic has increased during the past decade (10-14). Aminzadeh, Kashef and their collogues reported resistance rate of $50 \%$ and $62 \%$ to trimethoprim-sulfamethoxazole in Tehran $(13,14)$. The high resistance rate in our study seems to be result of widespread antibiotic usage of families even in the absence of prescription.

In this study the rate of resistance to amikacin was too low, therefore this agent can be a good choice for the empirical treatment of UTI in our population. Nitrofurantoin is considered as one of the oldest urinary anti-infective drugs in use, surprisingly, resistance to this drug remains minimal. As seen in Table 1, the overall resistance was $8 \%$. The lack of resistance may be related to the fact that nitrofurantoin has multiple mechanisms of action, requiring organisms to develop more than a single mutation in order to develop resistance. In addition, in Iran limited usage of this drug for treating uncomplicated cystitis especially in children may also be a contributing factor to the lack of development of widespread resistance $(15,16)$. Among bacterial isolates from children with UTI in our study resistance to meropenem was the least. This might be due to the limited usage of these antibiotics in our population.

Alarmingly high proportions of resistance to cephalosporins were found in our study. $64 \%$ and $68 \%$ to cefalotin, $36 \%$ and $64 \%$ to cefuroxime and cefixime, $34 \%$ and $56 \%$ to ceftriaxone for community and nosocomial isolates, respectively. The differences were statistically significant in both group to these antibiotics $(\mathrm{P}<0.05)$. In many countries such as our country, cephalosporins are the favorite antimicrobial agents for the empirical treatment of UTI and there is much evidence suggesting a relationship between prescribing habits and antibiotic resistance (17).

We found that $37 \%$ of isolates produced ESBL (32\% for 
community and $42 \%$ of nosocomial isolates).

Some surveys suggest that the overall rate of ESBL phenotypes is comparatively low. Distribution of ESBLpositive UTIs in Turkey was $3.6 \%$ in $2004,3.9 \%$ in 2005 , and $4.2 \%$ in 2006 (18). The ESBL rates are higher than some Middle East countries and other researchers from developed countries where ESBL production rates are less than 5\% (1822). The increasing frequency of ESBL phenotypes is an emerging problem and hospitalization, previous bacterial infection, urinary abnormalities, previous antimicrobial treatment (especially third-generation cephalosporins), recurrent tract infections, and presence of high-level and multidrug resistance have already been described as risk factors (23).

Our findings highlight the importance of access for clinicians especially in developing countries such as Iran to updated bacterial susceptibility data regarding commonly prescribed agents.

Table 1. Antimicrobial susceptibility testing results of $E$. coli isolates

\begin{tabular}{|c|c|c|c|c|c|c|c|c|c|c|c|}
\hline \multirow[t]{2}{*}{ Antibiotic } & \multicolumn{3}{|c|}{ Nosocomial } & \multicolumn{3}{|c|}{ Community } & \multicolumn{3}{|c|}{ All } & \multirow[t]{2}{*}{ MIC50 } & \multirow[t]{2}{*}{ MIC90 } \\
\hline & $\mathbf{R \%}$ & $1 \%$ & $\mathrm{S \%}$ & $\mathbf{R} \%$ & I\% & $\mathbf{S \%}$ & $\mathbf{R \%}$ & I\% & S\% & & \\
\hline $\begin{array}{r}\text { Trimethoprim/ } \\
\text { sulfamethoxazole }\end{array}$ & 78 & - & 22 & 90 & - & 10 & 84 & - & 16 & 32 & 32 \\
\hline Gentamicin & 18 & 10 & 72 & 30 & 6 & 64 & 24 & 8 & 68 & 0.5 & 32 \\
\hline Cefalotin & 52 & 12 & 36 & 64 & 4 & 32 & 58 & 8 & 34 & 256 & 256 \\
\hline Cefuroxime & 36 & - & 64 & 62 & 2 & 36 & 49 & 1 & 50 & 15 & 256 \\
\hline Cefixime & 34 & 2 & 64 & 58 & 6 & 36 & 46 & 4 & 50 & 1.25 & 256 \\
\hline Amikacin & 4 & - & 96 & 4 & 2 & 94 & 4 & 1 & 95 & 2 & 8 \\
\hline Nitrofurantoin & 10 & - & 90 & 6 & 2 & 92 & 8 & 1 & 91 & 8 & 32 \\
\hline Meropenem & 2 & 2 & 96 & - & - & 100 & 1 & 1 & 98 & 0.023 & 0.226 \\
\hline Ceftriaxone & 34 & - & 66 & 56 & - & 44 & 45 & - & 55 & 0.18 & 32 \\
\hline
\end{tabular}

$\mathrm{R}=$ Resistant

$\mathrm{I}=$ Intermediate

$\mathrm{S}=$ Sensitive

\section{REFERENCES}

1. Al-Tawfiq, J.A.; Anani, A.A. (2009). Antimicrobial susceptibility pattern of bacterial pathogens causing urinary tract infections in a Saudi Arabian hospital. Chemotherapy 55: 127-131.

2. Aminzadeh, Z.; Sadat Kashi, M.; Sha'bani, M. (2008). Bacteriuria by extended-spectrum Beta-lactamase-producing Escherichia coli and Klebsiella pneumoniae: isolates in a governmental hospital in South of Tehran, Iran. Iran J Kidney Dis. 2(4):197-200

3. Andrade, S.S.; Sader, H.S.; Jones, R.N.; Pereira, A.S.; Pignatari, A.C.; Gales, A.C. (2006). Increased resistance to first-line agents among bacterial pathogens isolated from urinary tract infections in Latin America: time for local guidelines? Mem Inst Oswaldo Cruz, Rio de Laneiro 101(7): 741-48

4. Arkam, M.; Shahid, M.; Khan, A.U. (2007). Etiology and antibiotic resistance pattern of community-acquired urinary tract infections in JNMC Hospital Aligarh, India. Ann Clin Microbiol Antimicrob 6:4

5. Arslan, H.; Azap Kurt, O.; Ergonul, O.; Timurkaynak, F. (2005). Urinary Tract Infection Study Group. Risk factors for ciprofloxacin resistance among E. coli strains isolated from community-acquired urinary tract infections in Turkey. J Antimicrob Chemother 56: 914-18S

6. Bonnet, R. (2004). Growing group of extended-spectrum betalactamases: the CTX-M enzymes. Antimicrob Agents Chemother 48:114

7. Bronzwaer, S.L.; Cars, O. and participants in the European Antimicrobial Surveillance System et al. (2002). A European study on the relationship between antimicrobial use and antimicrobial resistance. Emerg Infect Dis 8:278-282

8. Bush, K. (2008). Extended-spectrum beta-lactamases in North America, 1987-2006. Clin Microbiol Infect 14(suppl 1):134-143. 
9. Canton, R.; Novais, A.; Valverde, A.; Machado, E.; Peixe, L.; Baquero, F.; Coque, T.M. (2008). Prevalence and spread of extended-spectrum beta-lactamase-producing Enterobacteriaceae in Europe. Clin Microbiol Infect 14(suppl1):144-153.

10. Caracciolo, A.; Bettinelli, A.; Bonato, C.; Isimbaldi, C.; Tagliabue, A.; Longoni, L.; Bianchetti, M.G. (2011). Antimicrobial resistance among Escherichia coli that cause childhood community-acquired urinary tract infections in Northern Italy. Ital J Pediatr. 6;37:3.

11. Dromigny, J.A.; Nabeth, P.; Juergens-Behr, A.; Perrier-Gros-Claude, J.D. (2005). Risk factors for antibiotic-resistant Escherichia coli urinary tract infections in Dakar, Senegal. J Antimicrob Chemother 56: 236-39

12. Elder, J. (2007). Urinary tract infections. kliegman R, Behrman R ,Jenson $\mathrm{H}$ et al. "Nelson Text book of pediatrics" $18^{\text {th }}$ edition. Saunders 2223-2227

13. Erb, A.; Stürmer, T.; Marre, R.; Brenner, H. (2007). Prevalence of antibiotic resistance in Escherichia coli: overview of geographical, temporal, and methodological variations. Eur J Clin Microbiol Infect Dis 26: $83-90$

14. Gupta, K. (2003). Emerging antibiotic resistance in urinary tract pathogens. Infect Dis Clin North Am 17:243-259

15. Kashef, N.; Djavid, G.E.; Shahbazi, S. (2010). Antimicrobial susceptibility patterns of community-acquired uropathogens in Tehran, Iran. J Infect Dev Ctries 1;4(4):202-6

16. Ladhani, S.; Gransden, W. (2003). Increasing antibiotic resistance among urinary tract isolates. Arch Dis Child 88:444-445

17. Lindbäck, H.; Lindbäck, J.; Sylvan, S.; Melhus, A. (2010). Low frequency of antibiotic resistance among urine isolates of Escherichia coli in the community, despite a major hospital outbreak with Klebsiella pneumoniae producing CTX-M-15 in Uppsala County. Scand J Infect Dis. 42(4):243-8.

18. Moffett, S.E.; Frazee, B.W.; Stein, J.C.; Navab, B.; Maselli, J.; Takhar, S.S.; Gonzales, R. (2011). Antimicrobial resistance in uncomplicated urinary tract infections in 3 California EDs. Am J Emerg Med. [Epub ahead of print]

19. National Committee for Clinical Laboratory Standards. (2011). Performance standards for antimicrobial disk susceptibility tests.TwentyFirst edition. Informational Supplement M100-S21. CLSI, Wayne, PA, USA.

20. Philippon, A.; Labia, R.; Jacoby, G. (1989). Extended spectrum beta lactamases. Antimicrob Agents Chemother 33 : 1131-6

21. Randrianirina, F.; Soares, J.L.; Carod, J.F.; Ratsima, E.; Thonnier, V.; Combe, P.; Grosjean, P.; Talarmin, A. (2007). Antimicrobial resistance among uropathogens that cause community-acquired urinary tract infections in Antananarivo, Madagascar. J Antimicrob Chemother 59: 309-12

22. Sharifian, M.; Karimi, A.; Tabatabaei, S.R.; Anvaripour, N. (2006). Microbial Sensitivity Pattern in Urinary Tract infections in children: a single center experience of 1177 urine cultures. Jpn. J. Hnfect. Dis 59, 380-382

23. Topaloglu, R.; Er, I.; Dogan, B.G.; Bilginer, Y.; Ozaltin, F.; Besbas, N.; Ozen, S.; Bakkaloglu, A.; Gur, D. (2010). Risk factors in communityacquired urinary tract infections caused by ESBL-producing bacteria in children. Pediatr Nephrol. 25(5):919-25. Epub 2010 Feb 12. 